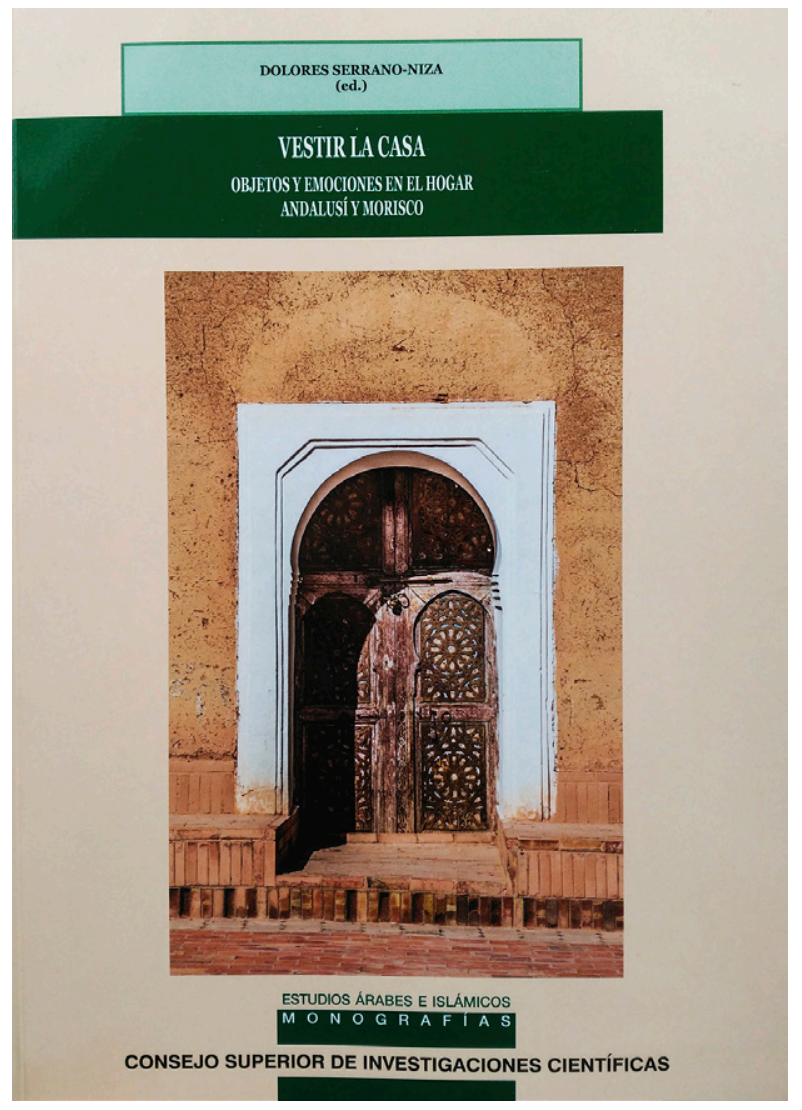

SERRANO-NIZA, Dolores (ed.)

\section{Vestir la casa. Objetos y emociones en el hogar andalusí y morisco}

Madrid: Consejo Superior de Investigaciones Científicas, 2019. 247 págs.

ISBN 978-84-00-10482-5

La excelente Editorial CSIC, en la colección de Monografías de Estudios Árabes e Islámicos, ha publicado este ańo un libro de contenido novedoso y necesario. Lo ha coordinado la profesora Dolores Serrano-Niza, del Departamento de Filología Clásica y Árabe de la Universidad de La Laguna.

El origen de la publicación fue el VI Seminario de Investigación Avanzada (SIA 16) organizado por el Instituto Universitario de Estudios de las
Mujeres de la Universidad de La Laguna (IUEMULL), dirigido por María Elena Díez Jorge y la propia Dolores Serrano-Niza. Es el producto del trabajo realizado por un grupo de siete investigadoras, la mayoría de las cuales se integra en el Proyecto de $\mathrm{I}+\mathrm{D}$ "De puertas para adentro: vida y distribución de espacios en la arquitectura doméstica (siglos XVXVI). Vida y Arquitectura (VIDARQ)," HAR201452248-P, cuya investigadora principal es María Elena Díez Jorge de la Universidad de Granada, dentro del Programa Estatal de Fomento de la Investigación Científica y Técnica de Excelencia del Ministerio de Fomento y Competitividad.

El punto de partida del conjunto de textos coincide con los principales objetivos del proyecto de investigación al que se adscribe, colocando el foco en cómo la vida y la arquitectura se imbrican en el espacio doméstico. Para ello se ha intentado reconstruir los interiores de las casas a través de los objetos que contenían, el conjunto de enseres y especialmente de textiles. A través de los textos jurídicos, inventarios de bienes, fuentes árabes y moriscas, palabras y cosas, las investigadoras han observado entre otras cuestiones, cómo el mobiliario en la mayoría de los hogares se caracterizaba por ser escaso y funcional, destinado a alcanzar un mínimo de habitabilidad. Con la inclusión de elementos organizadores de los espacios, como las cortinas o el estrado, que añadían a la información transmitida por los objetos, las diferentes ideas de habitabilidad. Y más allá, las autoras han querido profundizar en el conocimiento de las relaciones y los afectos entre quienes habitaron las casas, desembocando en el estudio de las emociones y de las comunidades emocionales. 
El libro se desarrolla a través de dos ejes principales. El primero se ha titulado "Construir una casa para habitarla" y comprende los tres primeros textos. Para comenzar, la profesora del Departamento de Filología Clásica, Francesa, Árabe y Románica de la Universidad de La Laguna, María Arcas Campoy, analiza las relaciones legales a las que estaban sometidas las mujeres andalusíes, especialmente los vínculos matrimonial y de servidumbre/ esclavitud, haciendo hincapié en la información sobre el entramado emocional que proporcionan las fuentes jurídicas. Descubre cómo al margen de las normas legales palpitan los afectos, los sentimientos, las emociones tanto positivas como negativas de las personas que compartían el espacio y la vida del hogar. Concluyendo que la casa es el mundo privado de los individuos que componen la sociedad, el escenario en el que afloran con mayor frecuencia e intensidad las relaciones entre mujeres y hombres.

A través del texto "Los inventarios notariales como fuente para el conocimiento de la arquitectura doméstica del Quinientos en Zaragoza," María Isabel Álvaro Zamora, del Departamento de Historia del Arte de la Universidad de Zaragoza, recrea la vida cotidiana de los propietarios de aquellos bienes. Y además del valor histórico que aporta el recorrido casi visual por las estancias de las casas y la detenida identificación y análisis funcional de cada objeto, es destacable su valor como fuente lingüística.

Finalmente, la académica de la Real Academia de la Historia, María Jesús Viguera Molins y Christine Mazzoli-Guintard, profesora de la Universidad de Nantes, en su texto "Disponer casa a la esposa (Tremecén, 747/1346) y cumplir la obligación matrimonial de la añafaga (nafaqa)" utilizan la fuente de Ibn Marzuq, al Musnad, para relatar cómo el sultán meriní del Magreb construye y decora una casa para cumplir con la obligación moral y religiosa de alojar conforme a su rango a la princesa de Túnez que era su prometida.
El segundo eje se ha denominado "Enseres y ajuares para un mundo de emociones" y comprende cuatro textos. En el primero, María Dolores Rodríguez Gómez, que es profesora del Departamento de Estudios Semíticos en la Universidad de Granada, titulado "Entre sedas y esparto: la posición social de las familias andalusíes del siglo XV a través de sus ajuares," muestra cómo en los hogares de las familias granadinas a fines del siglo XV, tanto pudientes como más humildes, los textiles son comparativamente más importantes que el mobiliario y otros enseres domésticos.

La editora de este libro, Dolores SerranoNiza, trabaja la misma línea en su capítulo "Textiles para el sueño. Ropa y ajuar morisco para hacer una cama," y reformula esos tejidos y sus nombres que llegados desde al-Andalus sobrevivieron en forma de arabismos. Palabras y descripciones — todas ellas relativas a los elementos con los que se hace una cama- custodiadas en documentos moriscos especialmente, pero también vivas en diccionarios cuyas definiciones pretende afinar en este trabajo.

A través de un buen número de documentos conservados en el Archivo del Patronato de la Alhambra y el Generalife, y algunos del Archivo General de Simancas, la investigadora de la Universidad de Granada, Aurora Molina Fajardo, en el texto "Cosas dejadas atrás. Objetos y emociones en la Granada del siglo XVI" reconstruye una historia de abandonos y confiscaciones de casas, ropas y enseres de quienes buscaban la supervivencia.

Para terminar, la profesora del Departamento de Historia del Arte de la Universidad de Granada, María Elena Díez Jorge, se ocupa de los pequeños en sus "Historias llenas de emociones: espacios y objetos de menores en las casas de moriscos y cristianos." Llama la atención sobre la necesidad de que los menores sean objeto de estudio científico, porque formaban parte de la sociedad y utilizaban 
los enseres de uso común además de los específicamente creados para ellos.

En definitiva, considero muy recomendable la lectura de este libro porque, utilizando algunas palabras de la última autora, la casa fue espacio de socialización, contenedor y creador de hábitos de comportamiento y de emociones que merecen todo nuestro esfuerzo de avance en el conocimiento.

Ana Aranda Bernal

Universidad Pablo de Olavide, Sevilla, España 